\title{
Total intravenous anesthesia with propofol augments the potency of mivacurium
}

\author{
[L'anesthésie intraveineuse totale avec le propofol augmente la puissance du \\ mivacurium]
}

Thomas M. Hemmerling MD DEAA, Nhien Le, Patrick Decarie, Julie Cousineau, David Bracco MD

Background: Little is known about the potentiating effect of propofol on neuromuscular blocking drugs. However, some animal studies indicate a dose-dependent increase of the potency of neuromuscular blocking drugs by propofol. This study compared mivacurium potency after five minutes and after 20 min of total intravenous anesthesia with propofol (TIVA propofol).

Methods: Twenty-eight patients were randomized into two groups, after approval of the Ethics Committee and written consent. Anesthesia was induced, in all patients, using remifentanil $0.5 \mu \mathrm{g} \cdot \mathrm{kg}^{-1} \cdot \mathrm{min}^{-1}$ for two minutes, after which: $3 \mathrm{mg} \cdot \mathrm{kg}^{-1}$ of propofol was injected; a laryngeal mask airway was inserted; and intermittent, positive pressure ventilation was initiated. Anesthesia was maintained using TIVA propofol (titrated using bispectral index monitoring to 40-45). Neuromuscular monitoring consisted of phonomyography at the adductor pollicis muscle. In Groups 5 min and 20 min, a tetanic stimulation of the ulnar nerve commenced after four minutes and after 19 min of TIVA, respectively, followed by controlled, single twitch stimulation at I $\mathrm{Hz}$ for one minute. Boli of $60,30,30$, and $30 \mu \mathrm{g} \cdot \mathrm{kg}^{-1}$ mivacurium, respectively, were administered (each drug increment was administered after the effect of the previous dose had caused a stable response), and single twitch stimulation continued at $0.1 \mathrm{~Hz}$. The dose-response curve was determined for both groups; potency was calculated using log-probit analysis. Data were presented as mean (SD) and were compared using two-sided analysis of variance, $P<0.05$.

Results: Patient characteristics were similar in the two groups. The corresponding $\mathrm{ED}_{50}$ and $\mathrm{ED}_{95}$ values were greater, at $76.7 \pm 12.4 \mu \mathrm{g}^{\mathrm{kg}}{ }^{-1}$ and $146.6 \pm 27.6 \mu \mathrm{g} \cdot \mathrm{kg}^{-1}$ for Group $5 \mathrm{~min}$, vs $46.7 \pm 12.2 \mu \mathrm{g}^{\mathrm{kg}} \mathrm{g}^{-1}$ and $10 \mathrm{I} .1 \pm 20.2 \mu \mathrm{g} \cdot \mathrm{kg}^{-1}$ for Group $20 \mathrm{~min}$, respectively.
Conclusions: After 20 min of TIVA propofol, the potency of mivacurium is approximately $50 \%$ greater than after five minutes of TIVA propofol. For clinical purposes, it is important, therefore, to consider the duration of TIVA propofol before determining the dose of neuromuscular blocking drug.

CAN J ANESTH 2008/55: 6 / pp 351-357

Contexte: Nous ne connaissons que très peu l'effet de potentialisation du propofol sur les curares. Néanmoins, certaines études animales indiquent une augmentation liée à la dose de la puissance des curares associée à l'utilisation de propofol. Cette étude compare la puissance du mivacurium après cinq minutes et après 20 min d'anesthésie intraveineuse complète avec propofol (TIVA propofol).

Méthode: L'aval du comité d'éthique et un consentement écrit obtenus, 28 patients ont été randomisés en deux groupes. L'anesthésie a été induite, chez tous les patients, à l'aide de rémifentanil $0,5 \mu \mathrm{g} \cdot \mathrm{kg}^{-1} \cdot \mathrm{min}^{-1}$ durant deux minutes, puis $3 \mathrm{mg} \cdot \mathrm{kg}^{-1}$ de propofol ont été injectés; un masque laryngé a été placé, et une ventilation en pression positive a été initiée. L'anesthésie a été maintenue en utilisant une TIVA propofol (titrée avec un monitorage d'index bispectral à 40-45). Le monitorage neuromusculaire était assuré par phonomyographie à l'adducteur du pouce. Dans les groupes 5 min et $20 \mathrm{~min}$, une stimulation tétanique du nerf cubital a été initiée après quatre minutes et après 19 min de TIVA, respectivement, suivie d'une stimulation transcutanée unique contrôlée à I $\mathrm{Hz}$ pour une minute. Des bolus de 60, 30, 30 et $30 \mu \mathrm{g} \cdot \mathrm{kg}^{-1}$ mivacurium, respectivement, ont été administrés (chaque addition

From the Department of Anesthesiology, Neuromuscular Research Group, McGill University, Montreal, Quebec, Canada.

Address correspondence to: Pr. Thomas Hemmerling, Neuromuscular Research Group (NRG), Montreal General Hospital, 1650 Cedar Avenue, Montreal, Quebec H3G 1B7, Canada. Phone: 514-934-1934, ext. 43030; Fax: 514-934-8249;

E-mail:thomashemmerling@hotmail.com

Dr. Hemmerling is recipient of the Bristol-Meyer-Squibb Award 2006; the study was performed using departmental funds and funds from this award. The data were presented in part at the Annual Meeting of the Canadian Society of Anesthesiology 2007, Calgary, June 22-26.

Competing interests: None declared.

Accepted for publication December 3, 2007.

Revision accepted March 13, 2008. 
$a$ été administrée après que l'effet de la dose précédente a causé une réaction stable), et la stimulation transcutanée unique a été maintenue à $0, I \mathrm{~Hz}$. La courbe de dose-réponse a été déterminée pour les deux groupes ; la puissance du médicament a été calculée avec une analyse log-probit. Les données ont été présentées en tant que moyenne (écart type) et ont été comparées en utilisant une analyse de variance à deux facteurs, $P<0,05$.

Résultats : Les caractéristiques des patients étaient semblables dans les deux groupes. Les valeurs correspondantes $E D_{50}$ et $E D_{95}$ étaient plus élevées, à $76,7 \pm 12,4 \mu \mathrm{g} \cdot \mathrm{kg}^{-1}$ et 146,6 $\pm 27,6 \mu \mathrm{g} \cdot \mathrm{kg}^{-1}$ pour le groupe $5 \mathrm{~min}$, vs $46,7 \pm 12,2 \mu \mathrm{g}^{\mathrm{kg}} \mathrm{g}^{-1}$ et $\mathrm{IOI}, \mathrm{I} \pm 20,2$ $\mu \mathrm{g} \cdot \mathrm{kg}^{-1}$ pour le groupe $20 \mathrm{~min}$, respectivement.

Conclusions: Après $20 \mathrm{~min}$ de TIVA propofol, la puissance du mivacurium est environ $50 \%$ plus élevée qu'après cinq minutes de TIVA propofol. C'est pourquoi il est important, à des fins cliniques, de prendre en compte la durée d'une TIVA propofol avant de déterminer la dose de curare à utiliser.

I $\mathrm{N}$ recent years, we have developed a greater understanding of the complex interactions between different anesthetic drugs, especially the interactions between volatile anesthetics and neuromuscular blocking agents (NMBAs). Several studies have shown that volatile anesthetics, and even nitrous oxide, enhance the potency of neuromuscular blocking drugs. ${ }^{1-3}$

It is generally thought that intravenous anesthetic agents, such as propofol, have little or no effect on the muscle-relaxing effect of neuromuscular blocking drugs. Interestingly, several recent reports indicate that profound anesthesia, using propofol, induces vocal cord paralysis, allowing the insertion of an endotracheal tube without the aid of neuromuscular blocking drugs. ${ }^{4-6}$ Good intubating conditions might clinically relate to a certain degree of relaxation of the larynx and diaphragm; however, objective neuromuscular monitoring, at these muscle groups, was not established in any of these previous studies. There is controversy as to whether a certain 'myorelaxant' action of propofol is based on a central or on a peripheral effect.

There is only one recent study, ${ }^{7}$ demonstrating that the duration of intravenous, propofol anesthesia, before the application of a given dose of a neuromuscular blocking drug, has an influence on the magnitude of the neuromuscular blockade; the longer the duration of anesthesia, before the dose is applied, the greater the intensity of the neuromuscular blockade achieved. However, that study did not determine the potency of the neuromuscular blocking drug.

The objective of this study was to examine the influ- ence of the duration of propofol-based anesthesia on the potency of mivacurium.

\section{Methods}

After having obtained approval by the local Ethics Committee and written patient consent, 28 patients, undergoing general surgery (herniorrhaphy, endoscopic surgery) or undergoing orthopedic procedures of moderate intensity, under general anesthesia using a laryngeal mask airway, were block-randomized into two groups (Groups $5 \mathrm{~min}$ and $20 \mathrm{~min}$ ). Surgeries included reconstruction of the anterior cruciate ligament, with a preparation time of at least $30 \mathrm{~min}$ between induction of anesthesia and beginning of surgery), No patient suffered from any cardiovascular or neuromuscular disease, and no patient had evidence of hepatic or renal dysfunction. Pregnant women and patients on drugs known to interact with neuromuscular blocking agents were excluded from the study. Patients with a body weight more than $115 \%$ of ideal body weight were also excluded from the study.

In Groups 5 min and $20 \mathrm{~min}$, the potency of mivacurium was determined five minutes (Group $5 \mathrm{~min}$ ) or 20 min (Group $20 \mathrm{~min}$ ) after the beginning of total intravenous anesthesia using propofol TIVA (Figure 1).

Before induction of anesthesia, a small piezo-electric microphone was attached to the thenar region of the adductor pollicis muscle (AP) for phonomyographic monitoring of the dominant hand, as previously described. ${ }^{8}$ In all patients, a laryngeal mask airway (size 4 for women, size 5 for men; LMA company, La Jolla, CA, USA) was inserted after administration of propofol $3 \mathrm{mg} \cdot \mathrm{kg}^{-1} \mathrm{iv}$, followed two minutes later with remifentanil infused at $0.5 \mu \mathrm{g} \cdot \mathrm{kg}^{-1} \cdot \mathrm{min}^{-1}$. Bispectral index (BIS; Aspect Medical Company, Norwood, $\mathrm{MN}$, USA) monitoring was also applied, and TIVA propofol was adjusted to a BIS target of 40-50. Intermittent positive pressure ventilation, using air/oxygen, was adjusted to maintain normal, end-tidal $\mathrm{CO}_{2}$. Non-invasive, blood pressure monitoring and a 3-lead electrocardiogram were used throughout the study. Blood pressure and heart rate values were recorded every minute.

Before the beginning of surgery, mivacurium potency was determined in both groups. According to group assignment, a tetanic stimulation, using a supramaximal stimulation current, was applied at the AP, with $50 \mathrm{~Hz}$ for three seconds (Figure 1). This was followed by control stimulation, at $\mathrm{l} \mathrm{Hz}$ for one minute, to stabilize the signal height, either five minutes or 20 min after beginning of anesthesia. Thereafter, single twitch stimulation, at a frequency of $0.1 \mathrm{~Hz}$, was used to determine the dose response curve of mivacu- 


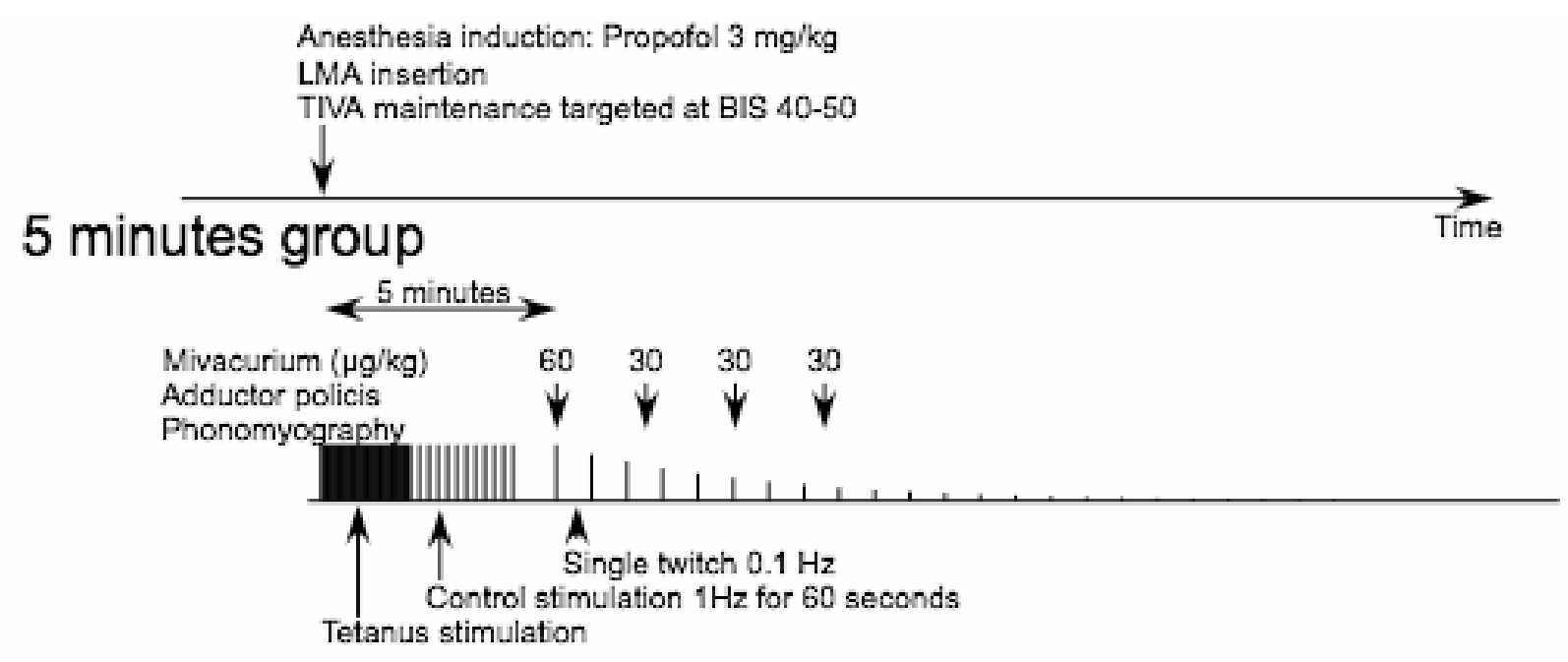

\section{0 minutes group}

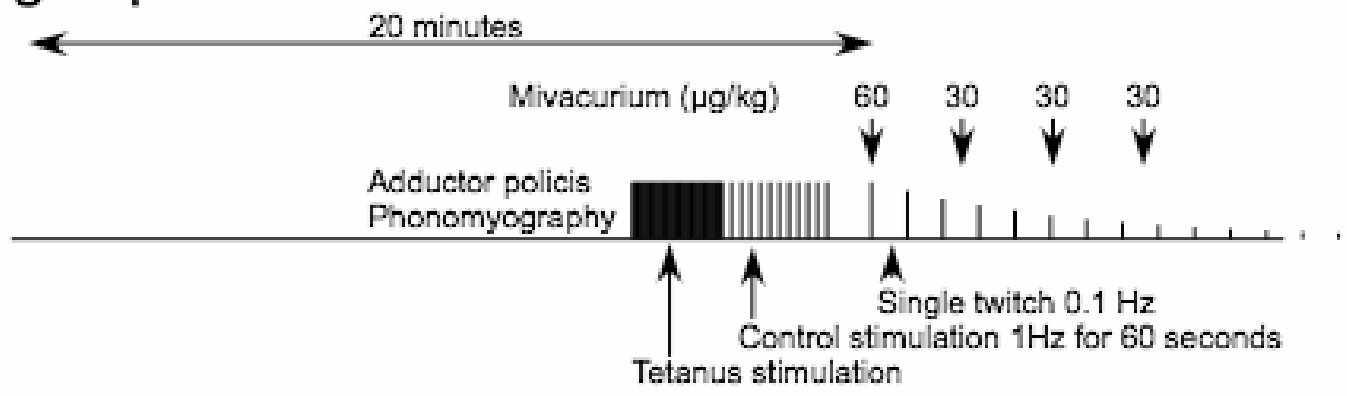

FIGURE 1 Study protocol; Group 5 min = determination of potency five minutes after the beginning of total intravenous anesthesia with propofol (TIVA propofol); Group $20 \mathrm{~min}=$ determination of potency $20 \mathrm{~min}$ after the beginning of TIVA propofol.

rium. Boli of $60,30,30$, and $30 \mu \mathrm{g} \cdot \mathrm{kg}^{-1}$ mivacurium, respectively, were administered; 9 each drug increment was administered after the effect of the previous dose had achieved a stable response (no more than $2.5 \%$ twitch height alteration over the course of one minute). Temperature was continuously monitored, with care taken to avoid loss of body or hand temperature by applying forced -air warming blankets, if necessary.

The primary outcome was the effect of the duration of intravenous anesthesia on the $\mathrm{ED}_{95}$ of mivacurium. Based on previous investigations by Lowry et al., ${ }^{10}$ the $\mathrm{ED}_{95}$ of mivacurium is $95 \mu \mathrm{g} \cdot \mathrm{kg}^{-1}$, with an error standard deviation of $28 \mu \mathrm{g} \cdot \mathrm{kg}^{-1}$. The statistical objective of the study, based on the previous investigation by Motamed et al., ${ }^{11}$ was to show an increase of mivacurium potency comparable to that shown with isoflurane, i.e., 40\%. A 1:1 allocation was chosen, and the minimal, clinically important difference of the $\mathrm{ED}_{95}$ value was considered to be $38 \mu \mathrm{g} \cdot \mathrm{kg}^{-1}$, with an alpha of 0.05 and a power of 0.9 . These parameters were entered into the DOE module of SAS (SAS Institute, Cary, NC, USA, version 7.0.1). A sample size of 24 patients was considered sufficient; nevertheless, an additional eight patients were recruited to accommodate for potential technical problems or incomplete data collection.

For each patient, based on the four points of twitch depression, a probit model was computed using weighted least squares regression: ${ }^{12,13}$

$$
\text { Probit }(\mathrm{Tl} \text { depression })=ß 0+ß 1 \ln (\text { dose })
$$

The individual $\mathrm{ED}_{50}$ and $\mathrm{ED}_{95}$ values were computed, based on the linear regression coefficients:

$$
\begin{gathered}
\mathrm{ED}_{50}=\mathrm{e}^{(-\beta 0 / \beta 1)} \text { and } \\
\operatorname{ED}_{95}=\mathrm{e}^{((\ln (19)-\beta 0) / \beta 1)}
\end{gathered}
$$

Patient and pharmacodynamic data were transferred into the JMP statistical package (version 7.0.1, SAS 
TABLE I (A) Patient characteristics*

\begin{tabular}{llll}
\hline & \multicolumn{2}{c}{ Group } & $P$ \\
& 5 min & 20 min & \\
\hline Age $(\mathrm{yr})$ & $49 \pm 17$ & $46 \pm 20$ & \\
Weight $(\mathrm{kg})$ & $69 \pm 15$ & $67 \pm 13$ & \\
Sex (F/M) & $9 / 5$ & $9 / 5$ & \\
Arterial pressure & $103 / 54 \pm$ & $105 / 59 \pm$ & \\
(systolic/diastolic) $[\mathrm{mmHg}]$ & $25 / 18$ & $22 / 11$ & \\
Heart rate (beats· $\left.\mathrm{min}^{-1}\right)$ & $56 \pm 8$ & $62 \pm 12$ & $\mathrm{NS}$ \\
BIS $(0-100)$ & $44 \pm 5$ & $46 \pm 6$ & $\mathrm{NS}$ \\
Hand temperature $\left({ }^{\circ} \mathrm{C}\right)$ & $35.4 \pm 0.3$ & $35.8 \pm 0.5$ & $\mathrm{NS}$ \\
Propofol $(\mathrm{mg})$ & $259 \pm 49$ & $376 \pm 48$ & 0.0001 \\
Remifentanil $(\mathrm{\mu g})$ & $88.4 \pm 10.6$ & $85.8 \pm 12.7$ & $\mathrm{NS}$ \\
\hline
\end{tabular}

BIS $=$ bispectral index.

Institute, Cary, NC, USA) and were analyzed using a two-sided analysis of variance (ANOVA). For all statistical analyses, a $P$ value $<0.05$ was considered to be significant. Data are presented as mean \pm SD.

\section{Results}

Thirty-two patients were recruited and consented to participate in this study. Four patients were excluded (two in each group), because insertion of laryngeal mask airway, without the aid of NMBAs, was not possible. The groups were similar with respect to age, weight, and sex distribution. At the time the data recording period began, prior to mivacurium administration, blood pressure, heart rate, and BIS values were similar between the two groups. The total dose of propofol, given before administration of mivacurium, was significantly higher after $20 \mathrm{~min}$ of propofol TIVA (Table I A and B).

On average, there was a good agreement in the weighted linear regression models, with an average $\mathrm{r}=0.968$. The calculated $\mathrm{ED}_{50}$ and $\mathrm{ED}_{95}$ values were significantly higher after five minutes TIVA $v s$ after 20 min propofol TIVA (Table II). The individual doseresponse calculations revealed significantly greater effect of mivacurium after 20 min of TIVA propofol compared to after five minutes TIVA propofol (Figure 2). No patient experienced an adverse event.

\section{Discussion}

This is the first study to determine the potency of a neuromuscular blocking drug after different durations

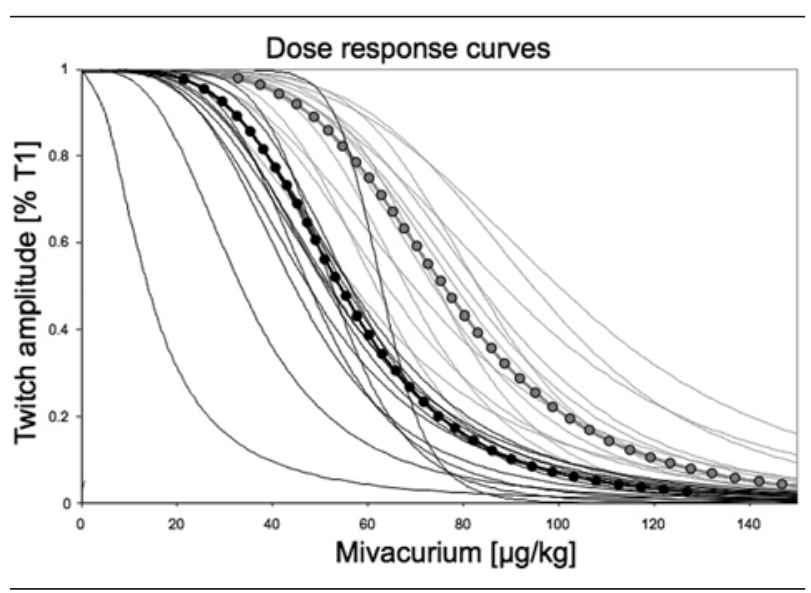

FIGURE 2 Dose-response curves for both groups (grey $=\mathbf{5}$ min; black = $20 \mathrm{~min}$ ); Individual curves (thin lines) and curves constructed using the average parameters (thick lines). Each drug increment was administered after the effect of the previous dose had achieved a stable response (no more than $2.5 \%$ twitch height alteration over the course of one minute).

of TIVA propofol. Mivacurium potency is significantly increased (approximately 1.5 fold) after $20 \mathrm{~min}$ of TIVA propofol, compared to a brief propofol infusion of five minutes.

One of the most recent studies, investigating the potency of mivacurium during TIVA propofol, was performed by Lowry et al. ${ }^{10}$ These authors determined mean $\mathrm{ED}_{50}$ and $\mathrm{ED}_{95}$ values of 53 and $95 \mu \mathrm{g} \cdot \mathrm{kg}^{-1}$, respectively. Lowry et al. ${ }^{10}$ induced loss of consciousness using fentanyl $1-2 \mu \mathrm{g} \cdot \mathrm{kg}^{-1}$ and propofol $1-3 \mathrm{mg} \cdot \mathrm{kg}^{-1}$, then assisted ventilation, to maintain normocapnia, using a breathing gas mixture of nitrous oxide and oxygen. Lowry et al. ${ }^{10}$ then administered propofol 6$10 \mathrm{mg} \cdot \mathrm{kg}^{-1} \cdot \mathrm{hr}^{-1}$ and established mechanomyographic monitoring at the AP. They allowed approximately ten minutes to achieve stable baseline neuromuscular responses before using the single dose technique to determine the potency. Therefore, it can be speculated that the actual duration of TIVA propofol, until the potency was determined, was similar to the duration of $20 \mathrm{~min}$ used in our study. It is interesting to note that the $\mathrm{ED}_{50}$ and $\mathrm{ED}_{95}$ values, determined in our study in Group $20 \mathrm{~min}$, are very similar to the equivalent, effective doses reported by Lowry et al. ${ }^{10}$ The slightly higher potency measured in Lowry's study

TABLE I (B) BIS values (presented mean \pm SD every minute in Group 5 min, every five minutes in Group 20 min)

\begin{tabular}{|c|c|c|c|c|c|c|c|c|c|c|}
\hline Group & $5 \mathrm{~min}$ & & & & & $20 \mathrm{~min}$ & & & & \\
\hline Time points (min) & 1 & 2 & 3 & 4 & 5 & 1 & 5 & 10 & 15 & 20 \\
\hline BIS $(0-100)$ & $42 \pm 4$ & $44 \pm 3$ & $41 \pm 5$ & $45 \pm 4$ & $40 \pm 5$ & $45 \pm 3$ & $47 \pm 3$ & $41 \pm 4$ & $42 \pm 5$ & $40 \pm 4$ \\
\hline
\end{tabular}

BIS $=$ bispectral index. Arterial pressure determined at the time of first mivacurium bolus administration. *Values are expressed as mean \pm SD. 
TABLE II Potency of mivacurium at the adductor pollicis muscle

\begin{tabular}{llll}
\hline & \multicolumn{2}{c}{ Groups } & $P$ \\
\hline & $5 \min$ & $20 \mathrm{~min}$ \\
ED50 $\left(\mu \mathrm{g} \cdot \mathrm{kg}^{-1}\right)$ & $76.7 \pm 12.4$ & $46.7 \pm 12.2$ & 0.0011 \\
ED95 $\left(\mu \mathrm{g} \cdot \mathrm{kg}^{-1}\right)$ & $146.6 \pm 27.6$ & $101.0 \pm 20.2$ & 0.0014 \\
\hline
\end{tabular}

Values are expressed as mean $\pm \mathrm{SD}$.

might be due to the known, small, potentiating effect of nitrous oxide, which has been measured to be around $15-20 \%{ }^{2}$

The potency for mivacurium was determined using the incremental dose method. ${ }^{9}$ Although it has been postulated by some authors that, in comparison to the single-dose method, the determination of the potency of shorter-acting neuromuscular blocking drugs produces lower values, when the incremental dose method is used, ${ }^{14,15}$ no previous study compared both methods for mivacurium. For the purpose of this study, comparing NMBA drug potency during two different durations of TIVA propofol, the use of the incremental dose method was deemed to be sufficiently accurate, since it was the difference, rather than the absolute value, of drug potency which was the focus of the investigation. The incremental dose response methodology has been recently used for dose-response studies of other neuromuscular blocking drugs, such as rocuronium and atracurium. ${ }^{16}$ Expected bias, due to the use of the incremental dose method, would have been the same for both groups. In addition, it is interesting to note that the potency, determined in our study for the 20 min group using the cumulative dose technique, is very similar to Lowry's findings, where mivacurium potency was determined using the singledose technique, after previous propofol-anesthesia of similar duration. ${ }^{10}$

Only one study has previously investigated the impact of the duration of intravenous anesthesia on neuromuscular blockade. Plaud et al..$^{7}$ examined the onset characteristics and peak effect of $0.1 \mathrm{mg} \cdot \mathrm{kg}^{-1}$ mivacurium, given immediately after tracheal intubation or given during TIVA propofol 15 min after intubation. These investigators found no change in onset time, but observed a $10-15 \%$ greater peak effect, after 15 min of propofol anesthesia, than immediately after intubation. Plaud et al. assumed, in their discussion, that this difference might have been due to changes with hemodynamic alterations, or changes in muscle blood flow. However, the amount of propofol and the depth of anesthesia, at the time of muscle relaxant administration, were not reported. Variations in the amount of propofol infused or the propofol plasma concentration, at the time of mivacurium administration, may have accounted for observed differences in peak effect.

Several confounding factors may influence the onset, peak effect, and recovery time of neuromuscular blocking agents, even when the same type of anesthesia is used. Nerve stimulation patterns and hemodynamic variations are the most important factors. Great care was taken in this study to establish a similar setup of nerve stimulation patterns and hemodynamic control for both groups. The staircase effect, during the length of control stimulation, will have an influence on onset time and peak effect. ${ }^{17-19}$ In both groups, following the same duration of titanic stimulation, potency was determined after single twitch stimulation occurred at $\mathrm{l} \mathrm{Hz}$ for one minute. Hand temperatures were similar in both groups, excluding the influences of differences in peripheral temperatures. ${ }^{20}$ The same depth of anesthesia, as shown by similar BIS values, was obtained during the study period in both groups. Although cardiac output was not measured in this study, similar heart rate and blood pressure values in both groups, at the time of determination of mivacurium potency, suggest similar hemodynamic conditions. In addition, potency in both groups was determined before the beginning of surgery, to avoid hemodynamic or hormonal changes induced by surgical stress.

Mivacurium was the muscle relaxant chosen for this study, because its onset of action appears to be less dependent on circulation to the muscle, in comparison to other non-depolarizing agents such as rocuronium. ${ }^{21}$ In 2007, mivacurium was withdrawn from the North American market for commercial reasons; it is still available in Europe. We assume that there could be a central or peripheral effect of propofol on neuromuscular blockade involved.

There is conflicting data concerning whether or not propofol elicits direct effects on muscle contractility, muscle excitability, or whether it potentiates neuromuscular blockade of non-depolarizing muscle relaxants. Propofol was initially formulated using Cremophor EL; it showed a potentiating effect on non-depolarizing, neuromuscular blocking drugs, both in vitro ${ }^{22}$ and in vivo. ${ }^{23,24}$ This effect, however, was found to be due to Cremophor EL, since it could not be shown with the new formulation of propofol as emulsion. ${ }^{25,26}$ Lebeda et al. ${ }^{27}$ showed, in an isolated rat hemidiaphragm model, that propofol potentiates the neuromuscular blocking effect of vecuronium, only at higher drug concentrations. Fujii et al. ${ }^{28}$ determined that, in subhypnotic and anesthetic doses, propofol decreases the contractility of canine dia- 
phragm. In addition, Kerz et al. ${ }^{29}$ and Kakinohana et al. ${ }^{30}$ demonstrated a depression of the H-reflex or F-wave persistence, respectively, in humans. Dueck et al. ${ }^{31}$ in a study in humans, confirmed the theory of propofol impairing the central portion, and not the peripheral portion, of the motor system. In patients under general anesthesia, using fentanyl and midazolam without neuromuscular blockade, he investigated the central portion of the motor system, by determining spinal F waves; and he recorded peripheral signals, by determining $M$ waves and mechanomyography of the thumb. The bolus administration of propofol reduced $\mathrm{F}$ waves significantly from baseline recordings, but did not alter $M$ waves or mechanomygraphic signals.

However, two studies point to a significant peripheral effect of propofol on muscle relaxation. Propofol seems to block voltage-gated skeletal muscle sodium channels in a concentration-dependant manner; ${ }^{32}$ although this effect is influenced by the excitation state of the muscle. An interesting study in rats, isolating nerve-gastrocnemius muscles ${ }^{33}$ suggests that propofol inhibits the neuromuscular transmission, pre-synaptically and directly, by acting on the muscle membrane. It potentiated the neuromuscular transmission of either pipecuronium or succinylcholine.

In conclusion, our findings propose a clinically relevant effect of propofol, and the duration of TIVA propofol, on the potency of non-depolarizing neuromuscular blocking drugs, in this case, mivacurium. The potency of mivacurium, after 20 min of TIVA propofol, is increased by approximately $50 \%$, in comparison to the potency of mivacurium, immediately administered after induction of anesthesia. Future studies will have to confirm these findings for different muscles (e.g., the corrugator supercilii muscle) and other neuromuscular blocking drugs (e.g., rocuronium).

\section{References}

1 Naguib M, Seraj M, Abdulrazik E. Pipecuroniuminduced neuromuscular blockade during nitrous oxidefentanyl, enflurane, isoflurane, and halothane anesthesia in surgical patients. Anesth Analg 1992; 75 : 193-7.

2 Fiset P, Balendran P, Bevan DR, Donati F. Nitrous oxide potentiates vecuronium neuromuscular blockade in humans. Can J Anaesth 1991; 38: 866-9.

3 Rupp SM, Miller RD, Gencarelli PJ. Vecuroniuminduced neuromuscular blockade during enflurane, isoflurane, and halothane anesthesia in humans. Anesthesiology 1984; 60: 102-5.

4 Erhan E, Ugur G, Gunusen I, Alper I, Ozyar B. Propofol - not thiopental or etomidate - with remifentanil provides adequate intubating conditions in the absence of neuromuscular blockade. Can J Anesth 2003; 50: 108-15.

5 Scheller MS, Zornow MH, Saidman LJ. Tracheal intubation without the use of muscle relaxants: a technique using propofol and varying doses of alfentanil. Anesth Analg 1992; 75: 788-93.

6 Klemola UM, Mennander S, Saarnivaara L. Tracheal intubation without the use of muscle relaxants: remifentanil or alfentanil in combination with propofol. Acta Anaesthesiol Scand 2000; 44: 465-9.

7 Pland B, Debaene B, Donati F. Duration of anesthesia before muscle relaxant injection influences level of paralysis. Anesthesiology 2002; 97: 616-21.

8 Hemmerling TM, Michaud G, Trager G, Deschamps S, Babin D, Donati F. Phonomyography and mechanomyography can be used interchangeably to measure neuromuscular block at the adductor pollicis muscle. Anesth Analg 2004; 98: 377-81.

9 Donlon JV Jr, Savarese JJ, Ali HH, Teplik RS.

Human dose-response curves for neuromuscular blocking drugs: a comparison of two methods of construction and analysis. Anesthesiology 1980; 53: 161-6.

10 Lowry DW, Mirakhur RK, Carroll MT, McCarthy GJ, Hughes DA, O'Hare RA. Potency and time course of mivacurium block during sevoflurane, isoflurane and intravenous anesthesia. Can J Anesth 1999; 46: 29-33.

11 Motamed C, Donati F. Sevoflurane and isoflurane, but not propofol, decrease mivacurium requirements over time. Can J Anesth 2002; 49: 907-12.

12 Litchfield JT Jr, Wilcoxon F. A simplified method of evaluating dose-effect experiments. J Pharamcol Exp Ther 1949; 53: 99-113.

13 Finney DJ. Probit Analysis, $3^{\text {rd }}$ ed. Cambridge: Cambridge University Press; 1971.

14 Gibson FM, Mirakhur RK, Lavery GG, Clarke RS. Potency of atracurium: a comparison of single dose and cumulative dose techniques. Anesthesiology 1985; 62: 657-9.

15 Gibson FM, Mirakhur RK, Clarke RS, Lavery GG. Comparison of cumulative and single bolus dose techniques for determining the potency of vecuronium. Br J Anaesth 1985; 57: 1060-2.

16 Xue F, Zhang $\Upsilon$, Liao X, Liu J, An G. A comparative study of the dose-response and time course of recovery of atracurium and rocuronium. Chin Med J (Engl) 2000; 113: 1019-21.

17 McCoy EP, Mirakhur RK, Connolly FM, Loan PB. The influence of the duration of control stimulation on the onset and recovery of neuromuscular block. Anesth Analg 1995; 80: 364-7.

18 Symington MJ, McCoy EP, Mirakhur RK, Kumar N. Duration of stabilization of control responses affects 
the onset and duration of action of rocuronium but not suxamethonium. Eur J Anaesthesiol 1996; 13: 377-80.

19 Deschamps S, Trager G, Mathieu PA, Hemmerling TM. The staircase phenomenon at the corrugator supercilii muscle in comparison with the hand muscles. $\mathrm{Br} \mathrm{J}$ Anaesth 2005; 95: 372-6.

20 Eriksson LI, Viby-Mogensen J, Lennmarken C. The effect of peripheral hypothermia on a vecuronium-induced neuromuscular block. Acta Anaesthesiol Scand 1991; 35: 387-92.

21 Audibert $G$, Donati F. The onset of rocuronium, but not of vecuronium or mivacurium, is modified by tourniquet inflation. Anesth Analg 1996; 82: 848-53.

22 Fragen RJ, Booij LH, van der Pol F, Robertson EN, Crul $J F$. Interactions of diisopropyl phenol (ICI 35868) with suxamethonium, vecuronium and pancuronium in vitro. Br J Anaesth 1983; 55: 433-6.

23 Robertson EN, Fragen RJ, Booij LH, van Egmond J, Crul JF. Some effects of diisopropyl phenol (ICI 35 868 ) on the pharmacodynamics of atracurium and vecuronium in anaesthetized man. Br J Anaesth 1983; 55: 723-8.

24 Wali FA. Effects of some intravenous anaesthetics on the contractile responses produced in the chick biventer cervicis skeletal muscle. Pharmacol Res Commun 1985; 17: 361-76.

25 De Grood PM, Van Egmond J, Van De Wetering M, Van Beem HB, Booij LH, Crul JF. Lack of effects of emulsified propofol ('Diprivan') on vecuronium pharmacodynamics--preliminary results in man. Postgrad Med J 1985; 61(Suppl 3): 28-30.

26 Nightingale P, Petts NV, Healy TE, Kay B, McGuinness $K$. Induction of anaesthesia with propofol ('Diprivan') or thiopentone and interactions with suxamethonium, atracurium and vecuronium. Postgrad Med J 1985; 61(Suppl 3): 31-4.

27 Lebeda MD, Wegrzynowicz ES, Wachtel RE. Propofol potentiates both pre- and postsynaptic effects of vecuronium in the rat hemidiaphragm. Br J Anaesth 1992; 68: 282-5.

28 Fujii $\Upsilon$, Hoshi T, Takabashi S, Toyooka H. Propofol decreases diaphragmatic contractility in dogs. Anesth Analg 1999; 89: 1557-60.

29 Kerz T, Hennes HJ, Feve A, Decq P, Filipetti P, Duvaldestin $P$. Effects of propofol on $\mathrm{H}$-reflex in humans. Anesthesiology 2001; 94: 32-7.

30 Kakinohana M, Fuchigami T, Nakamura S, Kawabata T, Sugahara K. Propofol reduces spinal motor neuron excitability in humans. Anesth Analg 2002; 94: 1586-8.

31 Dueck MH, Oberthuer A, Wedekind C, Paul M, Boerner $U$. Propofol impairs the central but not the peripheral part of the motor system. Anesth Analg 2003; 96: 449-55.

32 Haeseler G, Stormer M, Bufler J, et al. Propofol blocks human skeletal muscle sodium channels in a voltagedependent manner. Anesth Analg 2001; 92: 1192-8.

33 Abdel-Zaber AO, Askar FG. The myoneural effects of propofol emulsion (Diprivan) on the nerve-muscle preparations of rats. Pharmacol Res 1997; 36: 323-32. 